\title{
Bioconversion of Non-Detoxified Hemicellulose Hydrolysates to Xylitol by Halotolerant Yeast Debaryomyces nepalensis NCYC 3413
}

Bhaskar Paidimuddala and Sathyanarayana N Gummadi*

Applied and Industrial Microbiology Laboratory, Department of Biotechnology, IIT Madras, Chennai, India

\begin{abstract}
Lignocellulosic materials are one of the most abundant renewable resources whose exploitation for the production of biochemicals and biofuels is the major challenge in the area of industrial biotechnology due to inhibition of growth and product formation by the toxic compounds released upon their hydrolysis. Indeed the bioprocess that can produce industrial products from hemicellulose hydrolysates in the presence of toxic compounds is economical than the process which involves detoxification. In this study, the ability of halotolerant strain Debaryomyces nepalensis NCYC 3413 to convert non-detoxified xylose enriched hemicellulose hydrolysates from corn cobs, rice straw, sugarcane bagasse and wheat straw to xylitol was evaluated. It was found that this strain has the capability to grow in all hemicellulose hydrolysates and convert xylose to xylitol without detoxification of hydrolysates. The maximum xylitol concentration of $14.6 \mathrm{~g} \mathrm{~L}^{-1}$ was obtained from corn cobs and wheat straw with productivities of 0.16 and $0.20 \mathrm{~g}$ $\mathrm{L}^{-1} \mathrm{~h}^{-1}$ respectively at a yield of $0.30 \mathrm{~g} \mathrm{~g}^{-1}$. Whereas sugarcane bagasse and rice straw gave xylitol yields of 0.31 and $0.32 \mathrm{~g} \mathrm{~g}^{-1}$ respectively with $14.2 \mathrm{~g} \mathrm{~L}^{-1}$ maximum xylitol and productivities were calculated to be 0.20 and $0.15 \mathrm{~g} \mathrm{~L}^{-1} \mathrm{~h}^{-1}$ respectively. The presence of high glucose hindered xylitol production by producing ethanol. Based on our findings, we suggest that (i) $D$. nepalensis is a promising strain for ecofriendly xylitol production as it exhibits broad specificity to lignocellulose substrates, fermentation of mixed sugars and (ii) tolerance towards lignocellulosic inhibitors making the process more economical.
\end{abstract}

Keywords: Debaryomyces nepalensis NCYC 3413; Acid hydrolysis; Hemicellulose hydrolysates; Non detoxification; Ligno-sugars; Lignocellulosic inhibitors; Acetate; Acid soluble lignin; Xylitol; Ethanol

Abbreviations: LCM: Lignocellulosic Material; $\mathrm{HCH}$ : Hemicellulose Hydrolysate, CDW: Cell Dry Weight, 5-HMF: 5-hydroxy Methyl Furfural, ASL: Acid Soluble Lignin

\section{Introduction}

Lignocellulosic Materials (LCMs) are the most abundant, inexpensive and renewable raw materials typically composed of $45 \%$ cellulose, $30 \%$ hemicellulose, $20 \%$ lignin, $5 \%$ minerals etc. [1] can be exploited for the production of a wide range of value added products of industrial interest. Among them xylitol, a pentose alcohol has been used as a sugar substitute which has anticariogenic, microbiostatic and insulin independent metabolic nature [2-5]. A recent study on rats confirmed its antidiabetic nature [6]. It has been approved by the US Food and Drug Administration (FDA) as a safe food additive [7]. The extremely low Glycemic Index (GI) of 7 has made it a promising substituent for glucose which has GI of 100 [8]. The price of xylitol is $\$ 5-7 \mathrm{~kg}^{-1}$. The current value of xylitol market is \$340 million [9] with applications in sugar free gums, sugar free confectionaries, common foods and drinks, dietetic products, oral hygiene, pharma and cosmetic products, as well as in anti-cancer and anti-AIDS (betulin) products.

The current xylitol production involves the employment of high temperatures $\left(80-140^{\circ} \mathrm{C}\right.$ ) and pressures (up to $50 \mathrm{~atm}$ ) with expensive, toxic raney-nickel catalyst for the hydrogenation of xylose which is a non-economical and non-ecofriendly process. Hence, biotechnological production of xylitol employing lignocelluloses as substrates would be an ideal substitute for the chemical route [10]. Since xylose is a major sugar found in hemicellulosic fraction of LCMs, its conversion to xylitol provides an economically viable operation at large scale [11]. The demand-supply ratio for xylitol has been constantly rising for the past few years. But the ecofriendly exploitation of lignocelluloses for xylitol production is still a persistent challenge in the field of white biotechnology.
Since lignocelluloses differ in their composition and recalcitrant nature, which leads to the production of Hemicellulose Hydrolysates (HCHs) with various concentrations of sugars and inhibitors upon pretreatment [12]. None of the existing detoxification strategies are ideal since they neither remove inhibitors completely nor retain fermentable sugars entirely $[13,14]$. Hence, the use of microbes with higher inhibitor tolerance would be economical to avoid the loss of sugars and to exclude a costly and time consuming unit operation detoxification [15].

Previously, we isolated halotolerant yeast Debaryomyces nepalensis NCYC 3413, from rotten apple, which is capable of utilizing both hexoses and pentoses. This strain has shown to produce xylitol with $0.51 \mathrm{~g} \mathrm{~g}^{-1}$ yield and $0.72 \mathrm{~g} \mathrm{~L}^{-1} \mathrm{~h}^{-1}$ productivity when xylose was used as sole carbon source [16]. It could also grow in a broad range of $\mathrm{pH}$ (311) and temperature $\left(8-42^{\circ} \mathrm{C}\right)$. The salt tolerance up to $2 \mathrm{M} \mathrm{NaCl}, 3 \mathrm{M}$ $\mathrm{KCl}$ and $1 \mathrm{M} \mathrm{LiCl}$ is the remarkable property of this strain, maintained by the accumulation of glycerol, sorbitol and other polyols under hyperosmotic conditions [17]. The NADPH specific xylose reductase enzyme (EC 1.1.1.21) that converts xylose to xylitol, from this strain was characterized [18].

In this study, the major lignocelluloses such as corn cobs, sugarcane

*Corresponding author: Sathyanarayana N Gummadi, Professor, Applied and Industrial Microbiology Laboratory, Department of Biotechnology, Bhupat and Jyot Mehta School of Biosciences, Indian Institute of Technology Madras, Chennai 600 036, India, Tel: +91-44-2257-4114/+91-44-2257-6114; E-mail: gummadi@iitm.ac.in

Received June 23, 2014; Accepted July 28, 2014; Published August 04, 2014

Citation: Paidimuddala B, Gummadi SN (2014) Bioconversion of Non-Detoxified Hemicellulose Hydrolysates to Xylitol by Halotolerant Yeast Debaryomyces nepalensis NCYC 3413. J Microb Biochem Technol 6: 327-333. doi:10.4172/19485948.1000163

Copyright: $\odot 2014$ Finore I, et al. This is an open-access article distributed under the terms of the Creative Commons Attribution License, which permits unrestricted use, distribution, and reproduction in any medium, provided the original author and source are credited 
bagasse, rice straw and wheat straw were chosen for the evaluation of the fermentation capacity of $D$. nepalensis. Without detoxification, the hydrolysates rich in glucose obtained from corn cobs and wheat straw were used to study the influence of initial glucose on xylitol production and hydrolysates rich in xylose obtained from all four LCMs were used for the evaluation of xylitol production by $D$. nepalensis after xylose enrichment. Hence, the main originality of this work is the use of a novel halotolerant strain $D$. nepalensis for the conversion of various hemicellulose hydrolysates into value added compounds like xylitol and ethanol without any pretreatment after hydrolysis, yielding a cheaper bioprocess.

\section{Materials and Methods}

\section{Raw materials}

Corn cobs and rice straw were collected from Tirupati agriculture fields (Andhra Pradesh, India) and Chittoor agriculture fields (Andhra Pradesh, India) respectively. Sugarcane bagasse was obtained from local shops around IIT Madras, Chennai (Tamil Nadu, India) and Wheat straw from Muzaffarpur crop fields (Bihar, India) during the year 2013-2014.

\section{Preparation of hemicellulose hydrolysates}

The dry raw materials were ground in a mixer, passed through mesh screens and selected the particle size ranging from $0.02-0.1 \mathrm{~cm}$ for preparation of hydrolysates rich in glucose whereas $0.5-2 \mathrm{~cm}$ for hydrolysates rich in xylose. The ground biomass was mixed with $1 \%$ $(\mathrm{v} / \mathrm{v}) \mathrm{H}_{2} \mathrm{SO}_{4}$ at a ratio of $1 \mathrm{~g}$ of biomass to $20 \mathrm{ml}$ of acid solution (1:20) and autoclaved at $120^{\circ} \mathrm{C}, 103 \mathrm{kPa}$ pressure for $15 \mathrm{~min}$. After filtration by cheese cloth, the hydrolysates were neutralized by solid $\mathrm{NaOH}$ and concentrated by vacuum freeze drying in a lyophiliser (Christ Alpha 1-2 LD Freeze Dryer, UK) at $-45^{\circ} \mathrm{C}$ and were sterilized and stored at $4^{\circ} \mathrm{C}$ until further use. The concentrated $\mathrm{HCHs}$ were directly taken for fermentation without any detoxification. The precipitants formed after neutralization and concentration were removed by centrifugation at $6700 \mathrm{x} \mathrm{g}$ for $10 \mathrm{~min}$.

\section{ATR-FTIR analysis}

For comparative investigation of the structural changes within cell walls of selected LCMs and the effectiveness of dilute acid on the release of ligno-sugars (Sugars from lignocellulose), we recorded the ATR-FTIR spectra of dilute acid treated biomass with raw material as control, in duplicates on Bruker alpha ATR IR equipped with zinc fillnide crystal. For each sample a total scans of 24 , from wave number 4000 to $800 \mathrm{~cm}^{-1}$ in absorbance mode at $2 \mathrm{~cm}$ resolution were taken and we focused on the region corresponding to the hemicelluloses and lignin i.e. 1500 to $1800 \mathrm{~cm}^{-1}$. Results were interpreted by comparing with previous reported literature [19-24].

\section{Microorganism, maintenance and inoculum preparation}

Debaryomyces nepalensis NCYC 3413 was maintained on a solid YPP medium consisting of $10 \mathrm{~g} \mathrm{~L}^{-1}$ yeast extract, $20 \mathrm{~g} \mathrm{~L}^{-1}$ peptone and 5 $\mathrm{g} \mathrm{L}^{-1}$ pectin at $\mathrm{pH} 7.0$ and incubated at $30^{\circ} \mathrm{C}$ for $26 \mathrm{~h}$. A loopful of cells was transferred into the $50 \mathrm{ml}$ seed media (YPD), pH 7.0 in $250 \mathrm{ml}$ Erlenmeyer flask containing $10 \mathrm{~g} \mathrm{~L}^{-1}$ yeast extract, $20 \mathrm{~g} \mathrm{~L}^{-1}$ peptone and $20 \mathrm{~g} \mathrm{~L}^{-1}$ dextrose and incubated for $12 \mathrm{~h}$ in a rotatory shaker at $30^{\circ} \mathrm{C}$ and $180 \mathrm{rpm}$ [16].

\section{Medium and fermentation conditions}

The concentrated corn cobs and wheat straw hydrolysates rich in glucose were directly taken for fermentation with addition of $2 \mathrm{~g} \mathrm{~L}^{-1}$ yeast extract. But the concentrated hemicellulose hydrolysates rich in xylose from all four LCMs were enriched with xylose up to $50 \mathrm{~g} \mathrm{~L}^{-1}$ by taking external pure xylose and $\left(\mathrm{NH}_{4}\right)_{2} \mathrm{SO}_{4} 3 \mathrm{~g} \mathrm{~L}^{-1} ; \mathrm{K}_{2} \mathrm{HPO}_{4} 6 \mathrm{~g}$ $\mathrm{L}^{-1} ; \mathrm{Na}_{2} \mathrm{HPO}_{4} 3 \mathrm{~g} \mathrm{~L}^{-1}$; yeast extract $1 \mathrm{~g} \mathrm{~L}^{-1}$ were added along with trace elements. All the components were autoclaved separately and mixed subsequently such that the final medium volume was $20 \mathrm{ml}$ in a 100 $\mathrm{ml}$ Erlenmeyer flask. The initial $\mathrm{pH}$ of the medium was adjusted to 6.0 using $\mathrm{H}_{3} \mathrm{PO}_{4} .2 .5 \% \mathrm{v} / \mathrm{v}$ seed corresponding to $0.1 \mathrm{~g}$ Cell Dry Weight (CDW) $\mathrm{L}^{-1}$ from YPD was taken as inoculum. All the flasks were incubated at $30^{\circ} \mathrm{C}, 180 \mathrm{rpm}$ in a rotatory shaker. A single sample of 0.5 $\mathrm{ml}$ volume was collected in aseptic conditions at regular intervals of 24 $\mathrm{h}$ for 5 days and analyzed for metabolites by High Performance Liquid Chromatography (HPLC) and CDW at OD $600 \mathrm{~nm}$.

\section{Analytical methods}

The concentration of metabolites glucose, xylose, xylitol, arabinose, glycerol, acetate, HMF and furfural were estimated by HPLC (Jasco) equipped with refractive index detector using Aminex HPX-87H column (Bio-Rad, Richmond, USA) at $45^{\circ} \mathrm{C}$ with $0.01 \mathrm{~N} \mathrm{H}_{2} \mathrm{SO}_{4}$ as the mobile phase at a flow rate of $0.6 \mathrm{ml} \mathrm{min}^{-1}$ with injection volume of $20 \mu \mathrm{l}$. All samples were sterilized and filtered through $0.2 \mu \mathrm{m}$ nylon filters prior to injection. The lignin present in hydrolysate was estimated by the method modified from Lahdetie et al. [25] using UV-visible spectrophotometer at $290 \mathrm{~nm}$. The absorption maxima for Lignin (Product No. 370959; Sigma Aldrich) was found to be $290 \mathrm{~nm}$ (Shimadzu UV spectrophotometer) used as standard. The cells were pelleted by centrifugation at $2600 \times \mathrm{g}$ for $5 \mathrm{~min}$ and resuspended in autoclaved water and washed twice prior to measuring optical density $(\mathrm{OD})$ at $600 \mathrm{~nm}$. The $\mathrm{g} \mathrm{CDW} \mathrm{L^{-1 }}$ was determined by using the precalibrated correlation $\mathrm{CDW}=0.33 \times \mathrm{OD} 600 \mathrm{~nm} \times$ dilution factor [16].

\section{Results and Discussion}

\section{Preparation and composition of hemicellulose hydrolysates rich in glucose}

Intensified research has been done to develop many pretreatment strategies to digest hemicellulose into either oligo or monosaccharides [11]. Among them dilute acid pretreatment has been reported to be most advantageous by its pronounced effects on solubilisation of hemicellulose and subsequent release of monosaccharides. It also involves low investment and operational costs. Albeit, many acids have shown to be efficient, the cheap acid, sulfuric acid in the range of $0.5-1.5 \%$ at temperatures $121-160^{\circ} \mathrm{C}$ has been used widely [11]. No pretreatment method is best, since the formation of lignocellulosic inhibitors is inevitable. But compared to the existing methods dilute acid is cheap and useful to get the hydrolysates easily [11]. Table 1 represents the release of sugars and inhibitors from the hydrolysates at the set particle size. The release of xylose and glucose was higher from corn cobs than wheat straw before concentration. These hydrolysates were concentrated and found to be rich in glucose.

\section{Xylitol production with HCHs from corncobs and wheat straw}

Since glucose was the predominant sugar released we studied its influence on xylitol production from corncobs (Figure 1A) and wheat straw (Figure 1B) hydrolysates by $D$. nepalensis. It produced high amounts of ethanol than xylitol, with high glucose consumption rates from both hydrolysates (Table 2). These results were supported by the fermentation of mixed sugar substrates by same strain in synthetic 
Citation: Paidimuddala B, Gummadi SN (2014) Bioconversion of Non-Detoxified Hemicellulose Hydrolysates to Xylitol by Halotolerant Yeast Debaryomyces nepalensis NCYC 3413. J Microb Biochem Technol 6: 327-333. doi:10.4172/1948-5948.1000163

\begin{tabular}{|c|c|c|c|c|}
\hline & \multicolumn{2}{|c|}{ Corn cobs } & \multicolumn{2}{c|}{ Wheat straw } \\
\hline $\begin{array}{c}\text { Compound } \\
\text { (g L-1) }\end{array}$ & $\begin{array}{c}\text { Before } \\
\text { concentration }\end{array}$ & $\begin{array}{c}\text { After } \\
\text { concentration }\end{array}$ & $\begin{array}{c}\text { Before } \\
\text { concentration }\end{array}$ & $\begin{array}{c}\text { After } \\
\text { concentration }\end{array}$ \\
\hline Xylose & $7.75 \pm 0.3$ & 25.4 & $6.3 \pm 0.05$ & 22 \\
\hline Glucose & $15.5 \pm 0.7$ & 39 & $11.6 \pm 0.2$ & 45.8 \\
\hline Arabinose & $1.0 \pm 0.01$ & 3.1 & $3.3 \pm 0.05$ & 13.2 \\
\hline Acetic acid & $2.0 \pm 0.8$ & 4.5 & $2.2 \pm 0.17$ & 5.7 \\
\hline $\begin{array}{c}\text { Acid soluble } \\
\text { Lignin }\end{array}$ & $2.3 \pm 0.07$ & 6.8 & $3.7 \pm 0.08$ & 7.7 \\
\hline $5-H M F$ & $0.1 \pm 0.07$ & 0.3 & $0.08 \pm 0.01$ & 0.22 \\
\hline Furfural & $0.05 \pm 0.03$ & 0.07 & $0.08 \pm 0.06$ & 0.1 \\
\hline
\end{tabular}

Table 1: Composition of hydrolysates rich in glucose. Values before concentration presented are mean of triplicates \pm SD. The concentrated hydrolysates were taken for fermentation.
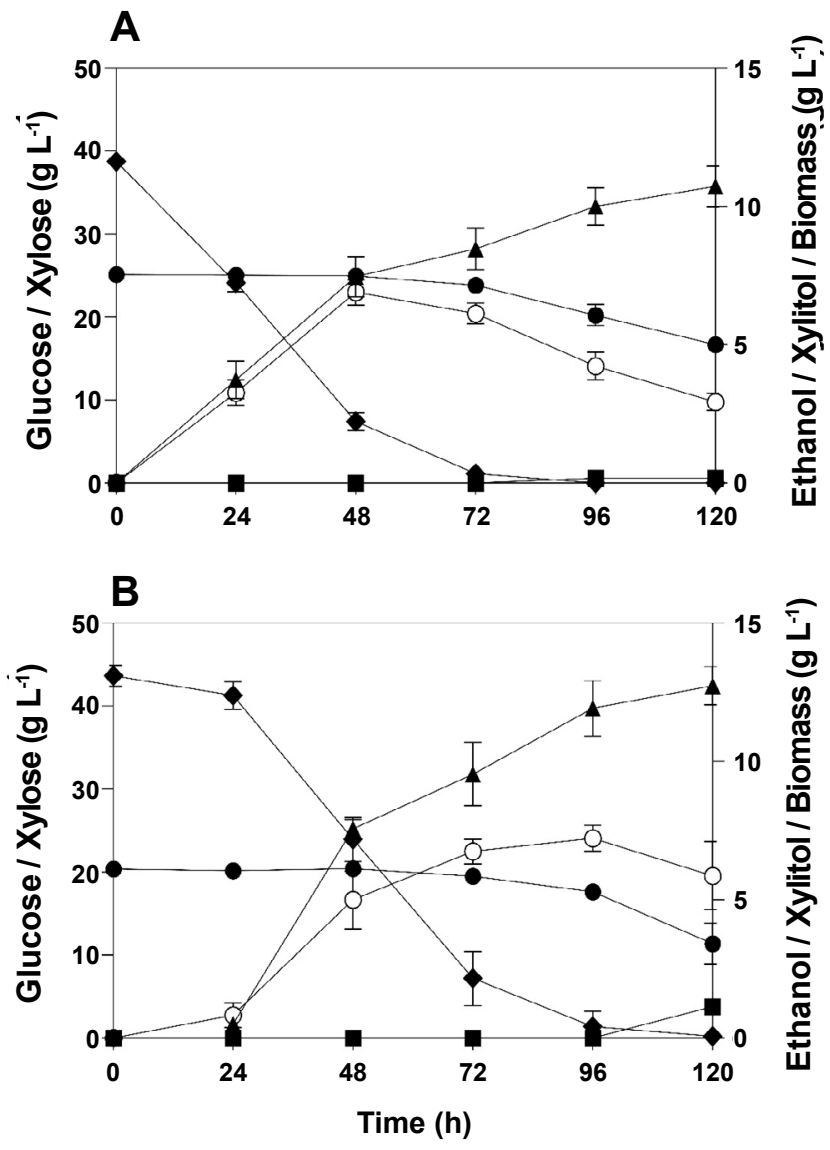

Figure 1: Time course of ethanol production by Debaryomyces nepalensis NCYC 3413 with non-detoxified hydrolysates rich in glucose. (A) corn cobs, (B) wheat straw; glucose $(\bullet)$, xylose $(\bullet)$, xylitol $(\boldsymbol{\square})$, biomass $(\boldsymbol{\Delta})$, ethano (O); Results are representative of three independent experiments.

medium [16]. D. nepalensis produced ethanol with $0.22 \mathrm{~g} \mathrm{~g}^{-1}$ yield and $0.14 \mathrm{~g} \mathrm{~L}^{-1} \mathrm{~h}^{-1}$ productivity from corn cobs hydrolysate whereas $0.20 \mathrm{~g}$ $\mathrm{g}^{-1}$ yield and $0.13 \mathrm{~g} \mathrm{~L}^{-1} \mathrm{~h}^{-1}$ productivity from wheat straw hydrolysates. Therefore, high glucose in the medium caused catabolite repression which led to poor utilization of xylose resulting in low xylitol yield. Similar observation has been reported in C. tropicalis [26]. But the promising ethanol yield obtained by this strain could also be useful for $2 \mathrm{G}$ ethanol production after efficient detoxification of hydrolysates and optimization of fermentation conditions. Since our aim was to obtain high xylitol yield by $D$. nepalensis in non-detoxified lignocellulosic hydrolysates, we increased the particle size taken for acid hydrolysis and obtained the hydrolysates rich in xylose.

\section{Preparation and composition of hemicellulose hydrolysates rich in xylose}

As can be seen in Table 3, under the tested conditions the corn cobs showed maximum release of xylose $24.5 \% \mathrm{w} / \mathrm{w}$ compared to others. Sugarcane bagasse and wheat straw gave mostly similar xylose yields $18 \% \mathrm{w} / \mathrm{w}$ and $16 \% \mathrm{w} / \mathrm{w}$ respectively. But rice straw released low xylose $13 \% \mathrm{w} / \mathrm{w}$. Apart from xylose; they also released other monosaccharides such as glucose and arabinose in low yields. All LCMs released the inhibitors of microbial growth namely acetate, Acid Soluble Lignin (ASL), 5-HMF and furfural upon acid hydrolysis. Corn cobs and sugarcane bagasse produced high levels of acetic acid 1.45-1.47 $\mathrm{g} \mathrm{L}^{-1}$ compared to other LCMs. Sugarcane bagasse, rice straw, corn cobs and wheat straw produced ASL $\left(\mathrm{g} \mathrm{L}^{-1}\right)$ 3.6, 2.8, 1.8 and 0.9 respectively. 5 -HMF was produced in high amounts by sugarcane bagasse and low in case of wheat straw. Furfural production was observed to be highest in corn cobs $\left(50 \mathrm{mg} \mathrm{L}^{-1}\right)$ and lowest in the case of rice straw $\left(27 \mathrm{mg} \mathrm{L}^{-1}\right)$.

\section{ATR-FTIR spectroscopic analysis}

ATR-FTIR a surface technique that penetrates to a depth of 1-2 $\mu \mathrm{m}$ was used to analyze cell wall structural changes of LCMs [19]. In sugarcane bagasse (Figure 2A) and wheat straw (Figure 2B), carbonyl band at $1740 \mathrm{~cm}^{-1}$, ascribed to hemicellulose [20] was drastically reduced upon hydrolysis due to its breakdown [21]. The $\mathrm{C}=\mathrm{O}$ stretching and aromatic vibration bands at $1640 \mathrm{~cm}^{-1}$ and at 1511 $\mathrm{cm}^{-1}$ [22] in wheat straw upon hydrolysis, were reduced, compared to raw material due to simultaneous release of lignin cross linked to hemicellulose. Whereas it was opposite in case of sugarcane bagasse, the appearance of bands at $1590-1660 \mathrm{~cm}^{-1}[23]$ and $1511 \mathrm{~cm}^{-1}$ indicates partial release of hemicellulose, exposing the lignin which led to its relocalization. It might be due to deposition of spherical lignin droplets on the surface of biomass produced during pretreatment at low $\mathrm{pH}$ and temperature $>150^{\circ} \mathrm{C}$ [24]. In case of corn cobs the bands corresponding to lignin (1515 to $1642 \mathrm{~cm}^{-1}$ ) were exposed (Figure 2C) upon hydrolysis indicating removal of hemicellulose resulting in re-localization of lignin. Unlike other tested LCMs rice straw (Figure 2D) showed similar pattern of bands with slight change in absorbance at all regions of spectra in both raw and treated materials indicated its high recalcitrant nature among the tested LCMs which is corroborated by the low concentration of xylose in its $\mathrm{HCH}$ as mentioned in Table 3. However,

\begin{tabular}{|c|c|c|}
\hline & Corn cobs & Wheat straw \\
\hline Glucose $\left(\mathrm{g} \mathrm{L}^{-1}\right)$ & $38.76 \pm 0.11$ & $43.7 \pm 1.25$ \\
\hline Xylose $\left(\mathrm{g} \mathrm{L}^{-1}\right)$ & $25.10 \pm 0.55$ & $20.4 \pm 0.52$ \\
\hline Arabinose $\left(\mathrm{g} \mathrm{L}^{-1}\right)$ & $3.1 \pm 0.20$ & $13.0 \pm 0.00$ \\
\hline Acetate $\left(\mathrm{g} \mathrm{L}^{-1}\right)$ & $4.2 \pm 0.10$ & $5.0 \pm 0.12$ \\
\hline Acid soluble Lignin $\left(\mathrm{g} \mathrm{L}^{-1}\right)$ & $6.6 \pm 0.84$ & $7.6 \pm 1.00$ \\
\hline Max. xylitol $\left(\mathrm{g} \mathrm{L}^{-1}\right)$ & $0.17 \pm 0.02$ & $1.14 \pm 0.21$ \\
\hline Max. glycerol $\left(\mathrm{g} \mathrm{L}^{-1}\right)$ & $3.13 \pm 0.15$ & $4.56 \pm 0.24$ \\
\hline Max. ethanol $\left(\mathrm{g} \mathrm{L}^{-1}\right)$ & $6.9 \pm 0.45$ & $7.2 \pm 0.46$ \\
\hline Ethanol yield $\left(\mathrm{g} \mathrm{g}^{-1}\right)$ & $0.22 \pm 0.01$ & $0.20 \pm 0.01$ \\
\hline Ethanol productivity $\left(\mathrm{g} \mathrm{L}^{-1} \mathrm{~h}^{-1}\right)$ & $0.14 \pm 0.01$ & $0.13 \pm 0.01$ \\
\hline Glucose consumption rate $\left(\mathrm{g} \mathrm{L}^{-1} \mathrm{~h}^{-1}\right)$ & $0.40 \pm 0.00$ & $0.36 \pm 0.01$ \\
\hline Overall Glucose utilization $(\%)$ & $100 \pm 0.00$ & $99.45 \pm 0.28$ \\
\hline Biomass yield $\left(\mathrm{g} \mathrm{g}^{-1}\right)$ & $0.27 \pm 0.01$ & $0.29 \pm 0.02$ \\
\hline
\end{tabular}

Table 2: Summary of fermentation of the non-detoxified hydrolysates rich in glucose by Debaryomyces nepalensis NCYC 3413. The byproduct ethanol was produced in high amounts and no utilization of xylose was observed due to presence of high glucose. Values presented are mean of triplicates \pm SD. 
Citation: Paidimuddala B, Gummadi SN (2014) Bioconversion of Non-Detoxified Hemicellulose Hydrolysates to Xylitol by Halotolerant Yeast Debaryomyces nepalensis NCYC 3413. J Microb Biochem Technol 6: 327-333. doi:10.4172/1948-5948.1000163

\begin{tabular}{|c|c|c|c|c|c|c|c|c|}
\hline \multirow{2}{*}{ Compound } & \multicolumn{2}{|c|}{ Corn cobs } & \multicolumn{2}{|c|}{ Rice straw } & \multicolumn{2}{|c|}{ Sugarcane bagasse } & \multicolumn{2}{|c|}{ Wheat straw } \\
\hline & $\mathrm{g} \mathrm{L}^{-1}$ & $\% w / w$ & $\mathrm{~g} \mathrm{~L}^{-1}$ & $\% w / w$ & $\mathrm{~g} \mathrm{~L}^{-1}$ & $\% w / w$ & $\mathrm{~g} \mathrm{~L}^{-1}$ & $\% w / w$ \\
\hline \multirow{2}{*}{ Xylose } & $12.3 \pm 0.64$ & $24.5 \pm 1.28$ & $6.5 \pm 0.50$ & $13.0 \pm 1.0$ & $9.0 \pm 0.30$ & $18 \pm 0.60$ & $8.12 \pm 0.14$ & $16.2 \pm 0.28$ \\
\hline & (33) & & $(23.2)$ & & (32) & & $(27.7)$ & \\
\hline \multirow{2}{*}{ Glucose } & $0.87 \pm 0.25$ & $1.73 \pm 0.50$ & $0.77 \pm 0.20$ & $1.53 \pm 0.41$ & $1.5 \pm 0.45$ & $2.9 \pm 0.90$ & $0.47 \pm 0.05$ & $0.9 \pm 0.11$ \\
\hline & (1.7) & & $(4.4)$ & & $(7.5)$ & & $(1.5)$ & \\
\hline \multirow{2}{*}{ Arabinose } & $1.9 \pm 0.30$ & $3.87 \pm 0.60$ & $0.4 \pm 0.53$ & $0.77 \pm 1.06$ & $0.53 \pm 0.15$ & $1.0 \pm 0.30$ & $1.3 \pm 0.35$ & $2.7 \pm 0.70$ \\
\hline & $(1.8)$ & & (1.3) & & (2) & & $(2.7)$ & \\
\hline \multirow{2}{*}{ Acetic acid } & $1.47 \pm 0.31$ & $2.94 \pm 0.06$ & $0.2 \pm 0.27$ & $0.4 \pm 0.54$ & $1.45 \pm 0.42$ & $2.9 \pm 0.84$ & $0.47 \pm 0.15$ & $0.94 \pm 0.30$ \\
\hline & $(6.3)$ & & (4) & & (6) & & (3.5) & \\
\hline \multirow{2}{*}{$\begin{array}{l}\text { Acid soluble } \\
\text { Lignin }\end{array}$} & $1.8 \pm 0.03$ & $3.6 \pm 0.06$ & $2.8 \pm 0.08$ & $5.6 \pm 0.17$ & $3.60 \pm 0.16$ & $7.2 \pm 0.32$ & $0.9 \pm 0.08$ & $1.8 \pm 0.16$ \\
\hline & $(4.1)$ & & $(8.4)$ & & $(10.8)$ & & $(2.7)$ & \\
\hline \multirow{2}{*}{$5-\mathrm{HMF}$} & $0.09 \pm 0.06$ & $0.18 \pm 0.12$ & $0.3 \pm 0.01$ & $0.6 \pm 0.02$ & $0.42 \pm 0.08$ & $0.84 \pm 0.16$ & $0.01 \pm 0.05$ & $0.02 \pm 0.1$ \\
\hline & $(0.1)$ & & $(0.8)$ & & (1) & & $(0.03)$ & \\
\hline \multirow{2}{*}{ Furfural } & $0.05 \pm 0.02$ & $0.1 \pm 0.04$ & $0.027 \pm 0.01$ & $0.05 \pm 0.02$ & $0.04 \pm 0.005$ & $0.08 \pm 0.01$ & $0.03 \pm 0.01$ & $0.06 \pm 0.02$ \\
\hline & $(0.04)$ & & $(0.02)$ & & $(0.03)$ & & $(0.05)$ & \\
\hline
\end{tabular}

Table 3: Composition of Hemicellulose hydrolysates rich in xylose.

Values presented are mean of triplicates \pm SD before concentration. Parentheses indicate the concentrated values upon vacuum freeze drying.

A

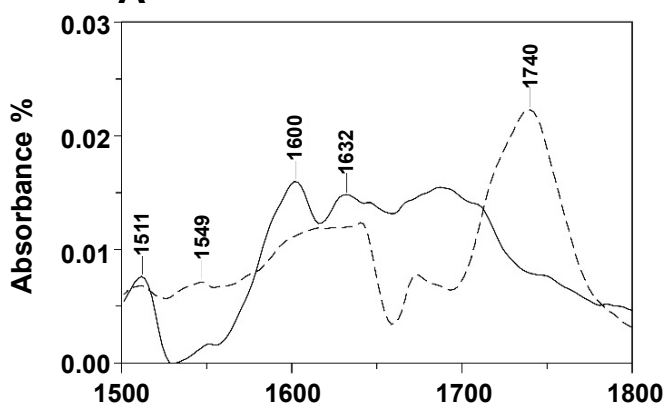

C

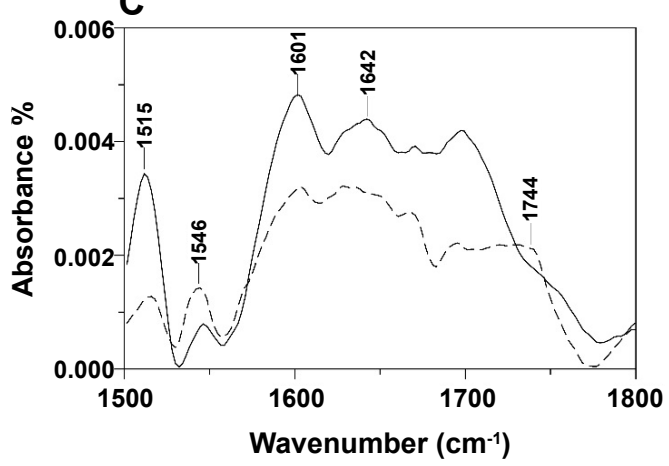

B

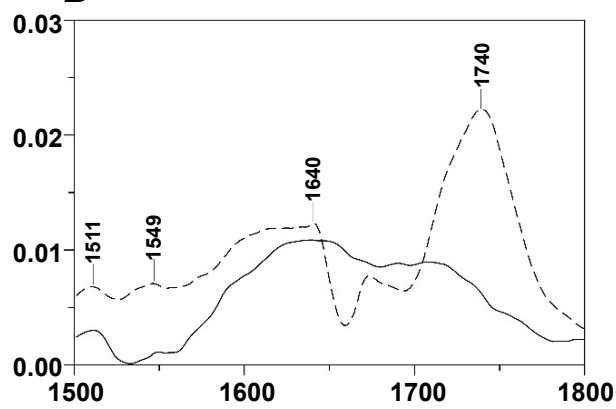

D

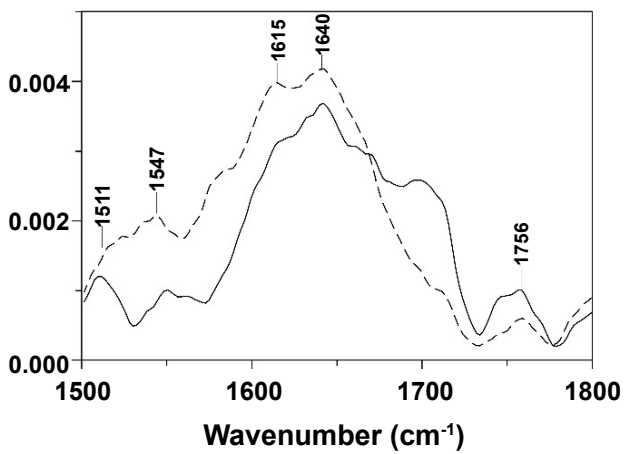

Figure 2: ATR- FTIR spectra of lignocellulosic materials. (A) sugarcane bagasse, (B) wheat straw, (C) corn cobs, (D) rice straw; Raw material (dotted line), dilute acid treated (thick line). The prominent structural changes observed in all tested LCMs after acid hydrolysis expect in rice straw indicated its low amenability towards the set of hydrolysis conditions employed. The band $1511-1642 \mathrm{~cm}^{-1}$ corresponds to lignin whereas $1740-1760 \mathrm{~cm}^{-1}$ ascribed to hemicelluloses. Analysis was performed in duplicates and best of the two was represented.

the overall results indicate that the acid hydrolysis conditions applied were enough to breakdown high fraction of hemicellulose in corncobs, moderate fraction in sugarcane bagasse and wheat straw, and low fraction in rice straw.

\section{Xylitol production from major lignocelluloses}

It is obvious that initial substrate concentration is a crucial factor influencing product yield and productivity [27]. Therefore, we conducted the fermentation studies by maintaining same initial xylose concentration in all $\mathrm{HCHs}$ to overcome the ambiguity caused by variations in initial substrate concentrations among the HCHs.
Nevertheless to evaluate the tolerance efficiency towards lignocellulosic inhibitors, lignocellulose compatibility of the strain and to make the bioprocess economical; detoxification, a prime unit operation was omitted. However, addition of external xylose, nitrogen source, macro and micro elements to the $\mathrm{HCH}$, made it diluted such that 5-HMF and furfural concentration became undetectable in the initial $\mathrm{HCH}$ fermentation broth. But the potent inhibitors which can establish synergistic inhibition [28], acetate and ASL remained in high amounts. Sugars and inhibitors composition in concentrated $\mathrm{HCHs}$ before taking for fermentation are represented in Table 3. 
Citation: Paidimuddala B, Gummadi SN (2014) Bioconversion of Non-Detoxified Hemicellulose Hydrolysates to Xylitol by Halotolerant Yeast Debaryomyces nepalensis NCYC 3413. J Microb Biochem Technol 6: 327-333. doi:10.4172/1948-5948.1000163
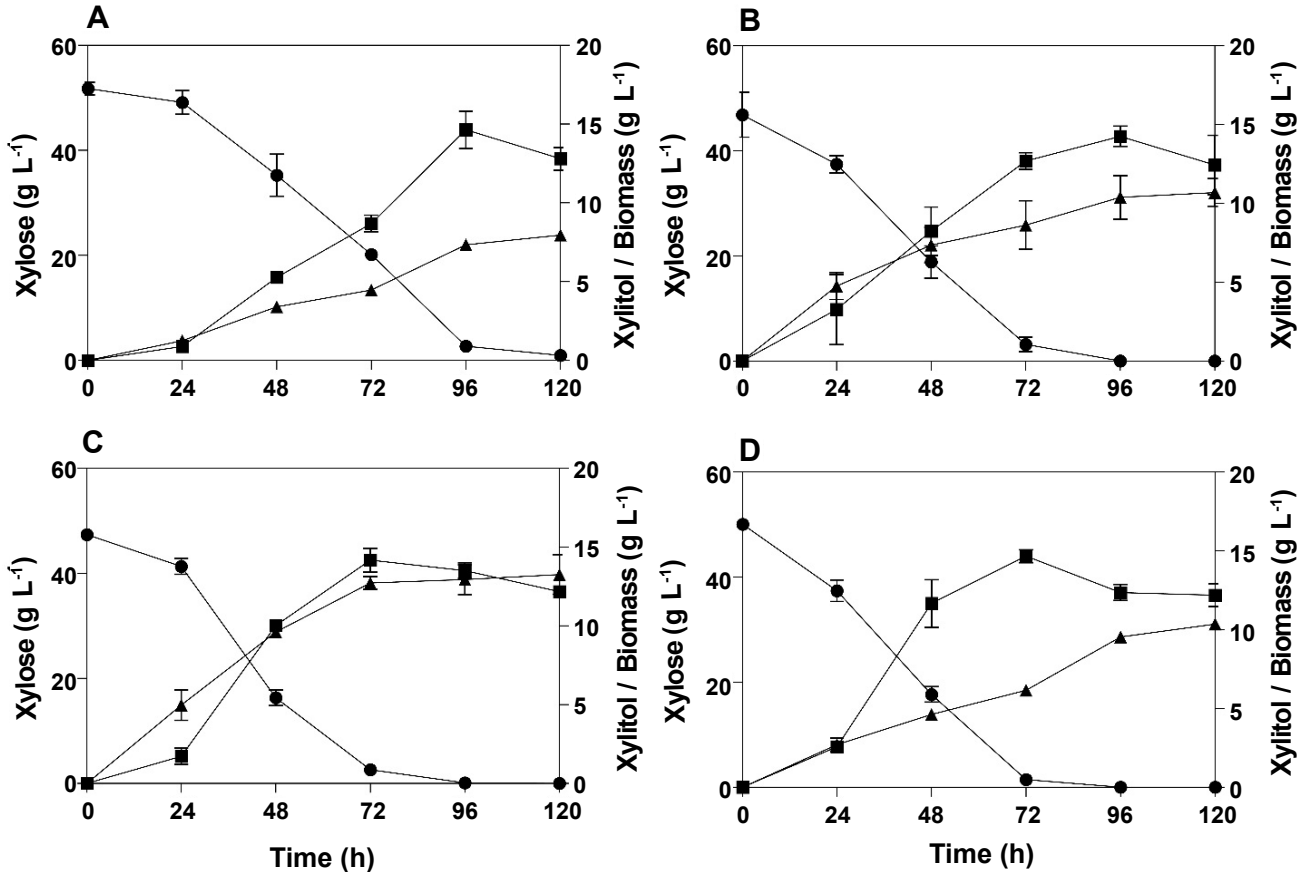

Figure 3: Time course of xylitol batch fermentation by Debaryomyces nepalensis NCYC 3413 with non-detoxified hemicellulose hydrolysates rich in xylose. (A) corn cobs, (B) rice straw; (C) sugarcane bagasse, (D) wheat straw; xylose $(\bullet)$, xylitol (ם), biomass ( $\mathbf{\Delta}$ ); Results are representative of three independent experiments.

\begin{tabular}{|c|c|c|c|c|}
\hline & Corn cobs & Rice straw & Sugarcane bagasse & Wheat straw \\
\hline Glucose $\left(\mathrm{g} \mathrm{L}^{-1}\right)$ & $1.8 \pm 0.10$ & $3.2 \pm 1.04$ & $4.1 \pm 0.36$ & $1.0 \pm 0.01$ \\
\hline Xylose $\left(\mathrm{g} \mathrm{L}^{-1}\right)$ & $51.7 \pm 1.19$ & $46.9 \pm 4.20$ & $47.4 \pm 1.09$ & $50.0 \pm 0.51$ \\
\hline Arabinose $\left(\mathrm{g} \mathrm{L}^{-1}\right)$ & $3.4 \pm 0.20$ & $1.3 \pm 0.10$ & $1.0 \pm 0.01$ & $1.7 \pm 0.03$ \\
\hline Acetate $\left(\mathrm{g} \mathrm{L}^{-1}\right)$ & $4.2 \pm 0.10$ & $2.3 \pm 0.12$ & $3.5 \pm 0.13$ & $2.0 \pm 0.09$ \\
\hline Acid soluble Lignin $\left(\mathrm{g} \mathrm{L}^{-1}\right)$ & $3.5 \pm 0.12$ & $7.6 \pm 0.14$ & $8.3 \pm 0.15$ & $2.0 \pm 0.12$ \\
\hline Max. xylitol $\left(\mathrm{g} \mathrm{L}^{-1}\right)$ & $14.6 \pm 1.18$ & $14.3 \pm 0.64$ & $14.2 \pm 0.76$ & $14.6 \pm 0.41$ \\
\hline Max. ethanol $\left(\mathrm{g} \mathrm{L}^{-1}\right)$ & $2.6 \pm 0.32$ & $2.1 \pm 0.51$ & $2.9 \pm 0.61$ & $1.4 \pm 0.15$ \\
\hline Max. glycerol $\left(\mathrm{g} \mathrm{L}^{-1}\right)$ & $3.8 \pm 0.77$ & $0.83 \pm 0.80$ & $0.48 \pm 0.10$ & $3.6 \pm 0.27$ \\
\hline Xylitol yield $\left(\mathrm{g} \mathrm{g}^{-1}\right)$ & $0.30 \pm 0.02$ & $0.32 \pm 0.02$ & $0.31 \pm 0.01$ & $0.30 \pm 0.02$ \\
\hline Xylitol productivity $\left(\mathrm{g} \mathrm{L}^{-1} \mathrm{~h}^{-1}\right)$ & $0.16 \pm 0.01$ & $0.15 \pm 0.01$ & $0.20 \pm 0.01$ & $0.20 \pm 0.01$ \\
\hline Xylose consumption rate $\left(\mathrm{g} \mathrm{L}^{-1} \mathrm{~h}^{-1}\right)$ & $0.42 \pm 0.01$ & $0.49 \pm 0.04$ & $0.49 \pm 0.01$ & $0.54 \pm 0.03$ \\
\hline Overall xylose utilization (\%) & $95.6 \pm 1.16$ & $100 \pm 0.00$ & $100 \pm 0.00$ & $100 \pm 0.00$ \\
\hline Biomass yield $\left(\mathrm{g} \mathrm{g}^{-1}\right)$ & $0.16 \pm 0.01$ & $0.23 \pm 0.04$ & $0.28 \pm 0.02$ & $0.21 \pm 0.01$ \\
\hline
\end{tabular}

Table 4: Summary of xylitol batch fermentation by Debaryomyces nepalensis NCYC 3413 with non-detoxified hemicellulose hydrolysates rich in xylose. Among all hydrolysates the overall xylose utilization and biomass yield were low in corn cobs due to prominent lignocellulosic inhibitors synergistic effect. Values presented are mean of triplicates \pm SD.

Maximum xylitol produced by our strain D. nepalensis NCYC 3413 was estimated to be in the range of $14.0-14.6 \mathrm{~g} \mathrm{~L}^{-1}$ in all tested LCMs. Xylitol yield was found to be $0.30 \mathrm{~g} \mathrm{~g}^{-1}$ from corn cobs $\mathrm{HCH}$ (Figure $3 \mathrm{~A}), 0.32 \mathrm{~g} \mathrm{~g}^{-1}$ from the rice straw $\mathrm{HCH}$ (Figure $3 \mathrm{~B}$ ), $0.31 \mathrm{~g} \mathrm{~g}^{-1}$ from sugarcane bagasse $\mathrm{HCH}$ (Figure $3 \mathrm{C}$ ) and $0.30 \mathrm{~g} \mathrm{~g}^{-1}$ from wheat straw $\mathrm{HCH}$ (Figure 3D). Productivity was calculated to be $0.15 \pm 0.01 \mathrm{~g} \mathrm{~L}^{-1}$ $\mathrm{h}^{-1}$ in corn cobs and rice straw whereas $0.20 \pm 0.01 \mathrm{~g} \mathrm{~L}^{-1} \mathrm{~h}^{-1}$ in case of sugarcane bagasse and wheat straw. The xylitol production from all tested LCMs was summarized in Table 4.

Among the natural xylitol producing microbes Candida species convert xylose to xylitol with high efficiency [29]. Misra et al. obtained $0.37 \mathrm{~g} \mathrm{~g}^{-1}$ xylitol yield and $0.15 \mathrm{~g} \mathrm{~L}^{-1} \mathrm{~h}^{-1}$ productivity using corn cob nondetoxified hydrolysates by adapted strain of C. tropicalis [30] which was mostly equal to xylitol production by $D$. nepalensis (Table 4). Ping et al. studied xylitol production by C. tropicalis CCTC M2012462 in non-detoxified corn cob hydrolysate medium consisting of $3.5 \mathrm{~g} \mathrm{~L}^{-1}$ acetate, $0.39 \mathrm{~g} \mathrm{~L}^{-1}$ furfural, and $0.42 \mathrm{~g} \mathrm{~L}^{-1} 5$-HMF. The obtained yield and productivity were $0.7 \mathrm{~g} \mathrm{~g}^{-1}$ and $0.46 \mathrm{~g} \mathrm{~L}^{-1} \mathrm{~h}^{-1}$ respectively [15], high compared to $D$. nepalensis. The presence of high acetate was responsible for low productivity by $D$. nepalensis (Table 4 ). Cell growth is drastically decreased when concentration of acetate is increased in case of $C$. parapsilosis [30]. Similar results were observed for D. nepalensis, with an extended lag phase. D. nepalensis has been shown to produce xylitol in a growth dependent manner [16]. The cofactor NADPH is required for the xylose reductase activity to convert xylose to xylitol and NADH for the downstream enzyme, xylitol dehydrogenase to convert xylitol to xylulose. The cofactor imbalance leads to the secretion of xylitol. NADPH produced by pentose phosphate pathway whose intermediates 
enter into TCA cycle to generate energy for cell growth. If the TCA cycle flux increases the growth associated production of xylitol increases. Since acetate inhibition was pronounced, it led to poor growth and resulted in low xylitol production $[28,31]$.

C. guilliermondii FTI 20037 has been shown to produce xylitol with $0.71 \mathrm{~g} \mathrm{~g}^{-1}$ yield, $0.56 \mathrm{~g} \mathrm{~L}^{-1} \mathrm{~h}^{-1}$ productivity from rice straw $\mathrm{HCH}$ containing inhibitors $\left(\mathrm{g} \mathrm{L}^{-1}\right) 1.82$ acetate, 0.515 -HMF and 0.13 furfural [32]. The low xylitol production obtained with $D$. nepalensis from rice straw $\mathrm{HCH}$ due to the presence of high acetate and ASL compared to the $\mathrm{HCH}$ used for above Candida strain. The observed extended lag phase was possibly due to the time needed for the strain to show tolerance towards the acetate that entered into the cell, by balancing the intracellular physiological pH (Figure 3B). Albeit, many species of Candida genus are best known natural xylitol producers, the rice straw $\mathrm{HCH}$ containing $\left(\mathrm{g} \mathrm{L}^{-1}\right) 53.8$ xylose, 19.5 glucose, 8.9 arabinose, the strains namely, C. boidinii Y-17213, C. blankii Y-17068, C. tropicalis IZ-5351, and C. guilliermondii IZ-1332 have been shown to produce negligible xylitol yields $\left(\mathrm{g} \mathrm{g}^{-1}\right) 0.17,0.18,0.20$ and 0.21 respectively, when compared to other Candida species which attributes to their intolerance towards lignocellulosic inhibitors [33]. When compared to these Candida strains, D. nepalensis tolerance towards inhibitors was higher and it utilized the total xylose within $72 \mathrm{~h}$ with xylose consumption rate of $0.49 \mathrm{~g} \mathrm{~L}^{-1} \mathrm{~h}^{-1}$ (Figure 3B).

In case of sugarcane bagasse $\mathrm{HCH}$ the acetic acid concentration has much less effect on fermentation below $5 \mathrm{~g} \mathrm{~L}^{-1}$ when compared to rice bran, eucalyptus as well as in synthetic medium [34]. So here the observed inhibition was obviously due to the presence of high levels of lignin oligomers and polymers and their synergism with acetic acid. D. nepalensis when compared to its close relative $D$. hansenii which has shown to produce xylitol from detoxified sugarcane $\mathrm{HCH}$ with $0.76 \mathrm{~g} \mathrm{~g}^{-1}$ yield and $0.44 \mathrm{~g} \mathrm{~L}^{-1} \mathrm{~h}^{-1}$ productivity [9], the production was nearly half due to presence of lignocellulosic inhibitors (Table 4). Nevertheless, innate xylose to xylitol conversion ability of the strain was less than $D$. hansenii, since it has given a maximum xylitol yield of $0.51 \mathrm{~g} \mathrm{~g}^{-1}$ and productivity of $0.72 \mathrm{~g} \mathrm{~L}^{-1} \mathrm{~h}^{-1}$ when pure xylose was used as substrate in synthetic medium [16].

Canilha et al. reported the highest xylitol production from detoxified wheat straw $\mathrm{HCH}$ composed of $\left(\mathrm{g} \mathrm{L}^{-1}\right) 30.5$ xylose, 1.6 acetate etc. by $C$. guilliermondii at optimized conditions with $0.9 \mathrm{~g} \mathrm{~g}^{-1}$ yield and $0.5 \mathrm{~g} \mathrm{~L}^{-1} \mathrm{~h}^{-1}$ productivity [35]. Though the present results are not comparable (Figure 3D), but intriguing, the possible high production after detoxification and subsequent optimization of fermentation conditions. Recently, Ramesh et al. by using the response surface methodology enhanced the xylitol yield from corncobs by Pachysolen tannophilus MTTC 1077 to $0.8 \mathrm{~g} \mathrm{~g}^{-1}$ [36]. On the other hand D. nepalensis was shown to grow, assimilate and ferment the sugars even in non-detoxified wheat straw unlike C. tropicalis AS2.1776. Moreover, addition of external xylose to the $\mathrm{HCHs}$ did not affect the evaluation process, validated by obtaining similar xylitol yields from all four tested $\mathrm{HCHs}$, though the variations in the concentration of ligno-sugars among the HCHs before xylose enrichment.

\section{Conclusions}

For the first time we report the assimilation and fermentation of hemicellulose hydrolysates without detoxification by halotolerant yeast Debaryomyces nepalensis NCYC 3413. We explored the broad specificity of this strain towards lignocellulosic substrates. Albeit, xylitol yield and productivity were moderate compared to other strains with non-detoxified hydrolysates, the strain has shown high tolerance towards lignocellulosic inhibitors. Therefore, strain adaptation and further optimization of fermentation conditions could increase the xylitol production at large scale. The efficient utilization of hexoses and pentoses present in hydrolysates by a single strain is an intriguing factor to integrate the production of ethanol and xylitol at industrial scale for the complete utilization of lignocellulosic sugars. In conclusion, this study revealed novel properties of $D$. nepalensis which are requisite for economical bioconversion of lignocelluloses to value added products.

\section{Acknowledgement}

This work was supported by research grant from Department of Biotechnology, Government of India. Authors acknowledge Sophisticated Analytical Instrumen Facility (SAIF), IIT Madras for ATR-FTIR analysis. BP acknowledges Indian Council of Medical Research (ICMR) for fellowship. BP acknowledges his friends Dhana and Rehaman for providing corn cobs and wheat straw respectively.

\section{References}

1. Saha BC (2003) Hemicellulose bioconversion. J Ind Microbiol Biotechnol 30 279-291.

2. Sakallioğlu O, Güvenç IA, Cingi C (2014) Xylitol and its usage in ENT practice. J Laryngol Otol

3. Ur-Rehman S, Mushtaq Z, Zahoor T, Jamil A, Anjum Murtaza M (2013) Xylitol; A review on Bio-production, Application, Health Benefits and Related Safety Issues. Crit Rev Food Sci Nutr

4. Maguire A, Rugg-Gunn AJ (2003) Xylitol and caries prevention--is it a magic bullet? Br Dent J 194: 429-436.

5. Uhari M, Kontiokari T, Niemelä M (1998) A novel use of xylitol sugar in preventing acute otitis media. Pediatrics 102: 879-884.

6. Rahman MA, Islam MS (2014) Xylitol improves pancreatic islets morphology to ameliorate type 2 diabetes in rats: a dose response study. J Food Sci 79 : H1436-1442.

7. Code of Federal Regulations, Title 21, Volume 3, (Rev. 01/04/2013) CITE: 21CFR172.395

8. Foster-Powell K, Holt SH, Brand-Miller JC (2002) International table of glycemic index and glycemic load values: 2002. Am J Clin Nutr 76: 5-56.

9. Prakash G, Varma AJ, Prabhune A, Shouche Y, Rao M (2011) Microbia production of xylitol from D-xylose and sugarcane bagasse hemicellulose using newly isolated thermotolerant yeast Debaryomyces hansenii. Bioresour Technol 102: 3304-3308.

10. Winkelhausen E, Kuzmanova S (1998) Microbial conversion of D-xylose to xylitol. J Ferment Bioeng 86: 1-14.

11. Gírio FM, Fonseca C, Carvalheiro F, Duarte LC, Marques S, et al. (2010) Hemicelluloses for fuel ethanol: A review. Bioresour Technol 101: 4775-4800.

12. Hendriks AT, Zeeman G (2009) Pretreatments to enhance the digestibility of lignocellulosic biomass. Bioresour Technol 100: 10-18.

13. Brás T, Guerra V, Torrado I, Lourenço P, Carvalheiro F, et al. (2014) Detoxification of hemicellulosic hydrolysates from extracted olive pomace by diananofiltration. Process Biochem 49: 173-180.

14. Palmqvist E, Hahn-Hägerdal B (2000) Fermentation of lignocellulosic hydrolysates I: inhibition and detoxification. Bioresour Technol 74: 17-24.

15. Ping Y, Ling HZ, Song G, Ge JP (2013) Xylitol production from non-detoxified corncob hemicellulose acid hydrolysate by Candida tropicalis. Biochem Eng $J$ 75: 86-91.

16. Kumar S, Gummadi SN (2011) Metabolism of glucose and xylose as single and mixed feed in Debaryomyces nepalensis NCYC 3413: production of industrially important metabolites. Appl Microbiol Biotechnol 89: 1405-1415.

17. Kumar S, Lal P, Gummadi SN (2008) Growth of halotolerant food spoiling yeas Debaryomyces nepalensis NCYC 3413 under the influence of $\mathrm{pH}$ and salt. Curr Microbiol 57: 598-602.

18. Kumar S, Gummadi SN (2011) Purification and biochemical characterization of a moderately halotolerant NADPH dependent xylose reductase from Debaryomyces nepalensis NCYC 3413. Bioresour Technol 102: 9710-9717.

19. Pinkerneil P, Güldenhaupt J, Gerwert K, Kötting C (2012) Surface-attached 
Citation: Paidimuddala B, Gummadi SN (2014) Bioconversion of Non-Detoxified Hemicellulose Hydrolysates to Xylitol by Halotolerant Yeast Debaryomyces nepalensis NCYC 3413. J Microb Biochem Technol 6: 327-333. doi:10.4172/1948-5948.1000163

polyhistidine-tag proteins characterized by FTIR difference spectroscopy. Chemphyschem 13: 2649-2653.

20. Gastaldi G, Capretti G, Focher B, Cosentino C (1998) Characterization and proprieties of cellulose isolated from the Crambe abyssinica hull. Ind Crops Prod 8: 205-218.

21. Thomsen $\mathrm{MH}$, Thygesen $\mathrm{A}$, Jørgensen $\mathrm{H}$, Larsen $\mathrm{J}$, Christensen $\mathrm{BH}$, et al. (2006) Preliminary results on optimization of pilot scale pretreatment of wheat straw used in coproduction of bioethanol and electricity. Appl Biochem Biotechnol 129-132: 448-60.

22. Gao AH, Bule MV, Laskar DD, Chen S (2012) Structural and therma characterization of wheat straw pretreated with aqueous ammonia soaking. J Agric Food Chem 60: 8632-8639.

23. Sun JX, Sun R, Sun XF, Su Y (2004) Fractional and physico-chemical characterization of hemicelluloses from ultrasonic irradiated sugarcane bagasse. Carbohydr Res 339: 291-300.

24. Selig MJ, Viamajala S, Decker SR, Tucker MP, Himmel ME (2007) Deposition of lignin droplets produced during dilute acid pretreatment of maize stems retards enzymatic hydrolysis of cellulose. Biotechnol Prog 23: 1333-1339.

25. Lahadetie A, Liitia T, Tamminen T, Jaaskelainen AS (2009) Reflectance UVVis and UV resonance raman spectroscopy in characterization of kraft pulps. Bioresources 4: 1600-1619.

26. Kastner JR, Eiteman MA, Lee SA (2001) Glucose repression of xylito production in Candida tropicalis mixed-sugar fermentations. Biotechnol Lett 23: 1663-1667.

27. Kang HY, Kim YS, Kim GJ, Seo JH, Ryu YW (2005) Screening and characterization of flocculent yeast Candida sp. HY200 for the production of xylitol from D-xylose. J Microbiol Biotechnol 15: 362-367.
28. Palmqvist E, Hahn-Hägerdal B (2000) Fermentation of lignocellulosic hydrolysates II: inhibitors and mechanisms of inhibition. Bioresour Technol 74 25-33.

29. Kim SY, Oh DK, Kim JH (1999) Evaluation of xylitol production from corn cob hemicellulose hydrolysates by Candida parapsilosis. Biotechnol Lett 21: 891895.

30. Misra S, Raghuwanshi S, Saxena RK (2013) Evaluation of corncob hemicellulosic hydrolysate for xylitol production by adapted strain of Candida tropicalis. Carbohydr Polym 92: 1596-1601.

31. Roberto IC, Sato S, de Mancilha IM (1996) Effect of inoculum level of xylito production from rice straw hemicellulose hydrolysate by Candida guilliermondii. $\mathrm{J}$ Ind Microbiol 16: 348-350.

32. Zea DVL, Mayerhoff IC, Roberto, Silva SS (1997) Xylitol production from rice straw hemicellulose hydrolysate using different yeast strains. Biotechnol Lett 19: 407-409.

33. Huang H, Guo X, Li D, Liu M, Wu J, et al. (2011) Identification of crucial yeast inhibitors in bio-ethanol and improvement of fermentation at high $\mathrm{pH}$ and high total solids. Bioresour Technol 102: 7486-7493.

34. Canilha L, Almeida e Silva JB, Felipe MG, Carvalho W (2003) Batch xylito production from wheat straw hemicellulosic hydrolysate using Candida guilliermondii in a stirred tank reactor. Biotechnol Lett 25: 1811-1814.

35. Ramesh T, Muthuvelayudham R, Kannan RR, Viruthagiri T (2013) Enhanced production of xylitol from corncob by Pachysolen tannophilus using response surface methodology. Int J Food Sci.

36. Zhuang J, Lin L, Yong S, Pang C (2012) Detoxification of wheat straw formic acid hydrolysis and xylitol production. Adv Mater Res 383: 5453-5457. 